\title{
Objeto de aprendizagem: A matemática das plantas de casas e mapas
}

Ana Paula Noro - Centro Universitário Franciscano - anaapdb@ yahoo.com.br Alcibíades Gazzoni - Centro Universitário Franciscano - agazzoni@ unifra.br

Carla Carvalho Lencina - Centro Universitário Franciscano - carla-lencina@ bol.com.br

Carmen Vieira Mathias- Centro Universitário Franciscano - carmen@ unifra.br

Leandra Anversa Fioreze - Centro Universitário Franciscano - leandra@ unifra.br Leila Brondani Pincolini - Centro Universitário Franciscano - leila@ unifra.br Paula Gabrieli Santos de Assumpção - Centro Universitário Franciscano paulinha_gaby@yahoo.com.br

Suélen Guterres - Centro Universitário Franciscano - suelenguterres@ yahoo.com.br

\section{Resumo}

Este artigo aborda a construção de um objeto de aprendizagem voltado para o ensino de escalas e proporções seguindo a metodologia da Rede Interativa Virtual de Educação (RIVED) do Ministério de Educação. Esse objeto foi construído com recursos da tecnologia multimídia e está disponível on-line no repositório do RIVED, possibilitando aos alunos e professores do ensino fundamental um subsídio no estudo deste tema.

Palavras-chave: Escalas, proporcionalidade, objeto de aprendizagem.

\section{Object of learning: The mathematics of plants and maps of houses}

\begin{abstract}
This article discusses the construction of an object of learning dedicated to the teaching of scales and proportions following the methodology of Interactive Virtual Network of Education (RIVED) of the Ministry of Education. This educational material was provided with resources of technology and multimedia is available online at the RIVED repository, allowing the students and teachers of elementary school a grant to study this issue.
\end{abstract}

Key-words: Scales, proportionality, the object of learning.

\section{Introdução}

Distintas pesquisas enfatizam que o uso do computador pode ser um grande aliado para o desenvolvimento cognitivo dos alunos (Balacheff ; Kaput,1996), (Basso, M. V., 2003), ( Fagundes, L. C.; Maçada, D.; Sato, L. S.; 1999). Mas, ao contrário do desejado, há uma carência de professores que utilizam o computador em suas aulas, além de se encontrarem escolas que ainda não possuem laboratório de informática, como se pode observar em levantamento realizado por pesquisas junto aos professores da educação básica.

Com a evolução da tecnologia e sua inserção nos diferentes contextos, verificase a necessidade de que esta inserção também aconteça nas escolas, cabendo aos pesquisadores de maneira geral o papel de selecionar e estabelecer novos parâmetros educacionais que visem a "modificações no trabalho de formulação de atividades 
didáticas que possam ser associadas ao computador ou outra mídia”, possibilitando ao aluno, desde a mais tenra idade, uma alfabetização tecnológica (Cabral, 2005, p.1).

Busca-se então discutir os novos problemas que são colocados constantemente aos profissionais da educação com a evolução da tecnologia. A Informática Educativa contribui nestas discussões, pois corresponde a uma ampla linha de pesquisa que prevê a inserção do computador no processo ensino-aprendizagem, nos seus diferentes níveis e modalidades de educação, bem como a verificação dos impactos desta inserção.

Diante disso, várias iniciativas em âmbito nacional e internacional estão sendo tomadas com vistas a inserir recursos tecnológicos no ensino da educação básica. Podem-se citar alguns repositórios de objetos virtuais de aprendizagem que estão disponíveis on line, tais como:

- CESTA - Coletânea de Entidades de Suporte ao uso de Tecnologia na Aprendizagem, da Universidade Federal do Rio Grande do Sul - UFRGS ${ }^{1}$.

- MERLOT - Multimedia Educational Resourt for Learning and Online Teaching, da Universidade de Nova Orleans ${ }^{2}$.

- LABVIRT - Laboratório Didático Virtual, da Universidade de São Paulo ${ }^{3}$.

- RIVED - Rede Interativa Virtual de Educação, vinculado ao Ministério da Educação $(\mathrm{MEC})^{4}$.

Neste artigo dar-se-á atenção especial ao RIVED, pois em nossa Instituição (Centro Universitário Franciscano - UNIFRA) existe uma das equipes parceiras que desenvolve objetos para o Ministério da Educação. $O$ grupo de pesquisa RIVED/UNIFRA tem o propósito de desenvolver ações contínuas com vista ao desenvolvimento de objetos de aprendizagem, apoiando e capacitando os profissionais da educação na utilização dos conteúdos digitais e avaliando os impactos dessa inserção no processo ensino-aprendizagem das distintas disciplinas da educação básica e, em especial, a Matemática.

Este trabalho trata da concepção e desenvolvimento do Objeto de Aprendizagem A matemática das plantas de casas e mapas por uma equipe interdisciplinar formada por alunos e professores do Centro Universitário Franciscano - Santa Maria, o qual está disponível on line na página do RIVED $^{4}$ e na página da UNIFRA ${ }^{5}$.

\section{RIVED e Objetos de Aprendizagem}

O RIVED é um programa da SEED (Secretaria de Educação à Distância), vinculada ao MEC (Ministério da Educação) que tem como objetivo produzir conteúdos pedagógicos digitais na forma de objetos de aprendizagem. Esses conteúdos digitais são públicos e irrestritos, disponíveis para download, visualização e reutilização, os quais primam por estimular diversas formas de raciocínio, provocando o desenvolvimento do pensamento crítico do estudante e aproveitando do potencial da informática frente às novas abordagens pedagógicas. A meta "é melhorar a aprendizagem das disciplinas da educação básica e a formação cidadã do aluno" (RIVED, 2007).

Willey (2000, p.4) define objetos de aprendizagem como "as any entity, digital or non-digital, which can be used, re-used or referenced during technology supported

\footnotetext{
${ }^{1}$ Disponível em: <http://www.cinted.ufrgs.br/CESTA/cestaconsulta.html>

${ }^{2}$ Disponível em: <http://www.merlot.org/merlot/index.htm>

${ }^{3}$ Disponível em: <http://www.labvirt.futuro.usp.br>

${ }^{4}$ Disponível em: <http://rived.mec.gov.br/>

${ }^{5}$ Disponível em: <http://www.unifra.br/rived >

V. 6 № 1, Julho, 2008
} 
learning" "6ssa definição inclui os recursos digitais que são distribuídos pela rede, seja ele de pequeno ou grande porte. Segundo o que está disponível no site do RIVED:

\begin{abstract}
Um objeto de aprendizagem é qualquer recurso que possa ser reutilizado para dar suporte ao aprendizado. Sua principal idéia é "quebrar" o conteúdo educacional disciplinar em pequenos trechos que podem ser reutilizados em vários ambientes de aprendizagem. Qualquer material eletrônico que provém informações para a construção de conhecimento pode ser considerado um objeto de aprendizagem, seja essa informação em forma de uma imagem, uma página HTM, uma animação ou simulação (RIVED, 2007).
\end{abstract}

A busca de uma qualificação no processo ensino-aprendizagem faz-nos refletir sobre a inserção no Currículo Escolar de aplicativos educacionais com vistas a maximizar a compreensão de conceitos básicos do ensino fundamental e, assim, melhorar o aprendizado de disciplinas consideradas difíceis e como conseqüência, temidas, como a matemática.

\title{
3. Concepção e desenvolvimento do objeto de aprendizagem
}

O presente trabalho foi desenvolvido por uma equipe pedagógica formada por professores e acadêmicos do Curso de Matemática e por uma equipe de apoio técnico, com o intuito de elaborar um objeto virtual de aprendizagem para aplicação no ensino de escalas e proporções, para alunos do ensino fundamental, seguindo a metodologia RIVED. Além disso, pretende-se contribuir para que o futuro professor de Matemática (acadêmico do curso) tenha a possibilidade de discutir o papel do computador e sua importância no processo ensino-aprendizagem da Matemática, bem como possibilitar em seu processo formativo a construção de objetos de aprendizagem. Outra preocupação de nosso grupo é a de que nossos acadêmicos possam fazer uma posterior utilização nas escolas, por ocasião dos estágios do curso, analisando os resultados desta inserção.

Na concepção do objeto, levamos em conta o público alvo, a forma como o conteúdo será apresentado, em que momento o objeto será usado e qual a duração do tempo de sua utilização, a forma de interação com o objeto e principalmente procuramos proporcionar a relação fundamental entre os problemas e os conhecimentos dos alunos, levando em conta as fases em que os alunos estão passando. Neste sentido, nos apoiamos em Vergnaud (1996) que coloca que a psicologia intervém para proporcionar a relação fundamental entre problemas e conhecimentos, entre cada uma das fases que os alunos estão passando e também na escolha mais adequada possível das situações que se apresentam aos alunos.

Buscamos então pesquisar quais eram as situações de vida dos alunos, de uma maneira geral, em que os problemas concretos estavam relacionados aos conteúdos de escalas e proporcionalidade. Por isso, optamos por enfocar no objeto de aprendizagem plantas de casas e mapas.

Por exemplo, no quotidiano, quando uma família quer construir ou comprar um imóvel ou uma indústria quer produzir um objeto, este imóvel ou este objeto é projetado e desenhado, o que significa determinar ou verificar suas dimensões ou o processo de construção, etc. Para os imóveis ou objetos são feitos plantas ou croquis onde são mencionadas as escalas que são utilizadas. Se a escala for 1:50 (um para cinqüenta) o

\footnotetext{
${ }^{6}$ Tradução: Como uma entidade, digital ou não, que pode ser usada, reusada ou referenciada durante a aprendizagem suportada por tecnologia.

V. 6 № 1, Julho, 2008
} 
que isto significa? O que ela pretende informar? As medidas nas plantas são proporcionais às medidas correspondentes na casa real? A figura da planta desenhada na escala 1:50 é semelhante àquela feita na escala 1:100? Pelo exposto acima o interessante para um aluno entre 10 e 13 anos é perceber que tudo o que se constrói, antes é feito um modelo, onde conteúdos matemáticos podem ser explorados. Por exemplo, nas áreas territoriais, há a necessidade de serem feitos mapas geográficos para a representação dos limites de cada região, estado ou nação, bem como auxiliar no dimensionamento e comparação de áreas, mostrar densidades demográficas e auxiliar a localização desta região, estado ou nação em relação às demais.

O tema foi enfocado devido a sua importância no ensino de Matemática, pois a proporcionalidade e a escala estão presentes em muitas situações reais. Observa-se uma variedade de situações em que se faz necessário a mobilização de certos processos cognitivos que envolvem e colocam em prática os conceitos e noções relacionadas à proporcionalidade. Tinoco (1996), coloca que o conceito de proporcionalidade é essencial ao aprendizado de muitos conteúdos de diversas disciplinas ensinadas na educação básica e no terceiro grau (Geografia, Física, Química, Farmácia, etc.).

O objeto de aprendizagem contempla recursos da tecnologia multimídia. Escolhido o assunto, a modelagem foi feita via técnica de storyboard. A navegação no objeto é um roteiro guiado, ou seja, um caminho pré-determinado para preservar os prérequisitos do conteúdo. A partir do modelo, a implementação foi feita em Flash e a distribuição via web.

\section{Objeto de aprendizagem: A matemática das plantas de casas e mapas}

O objeto: A matemática das plantas de casas e mapas apresenta na página de abertura Luca (personagem principal) convidando o usuário a fazer um passeio, conforme mostra a figura 1. Durante o passeio, o aluno é convidado a ler e interpretar estórias sobre plantas baixas de imóveis ou mapas, devendo responder alguns questionamentos.

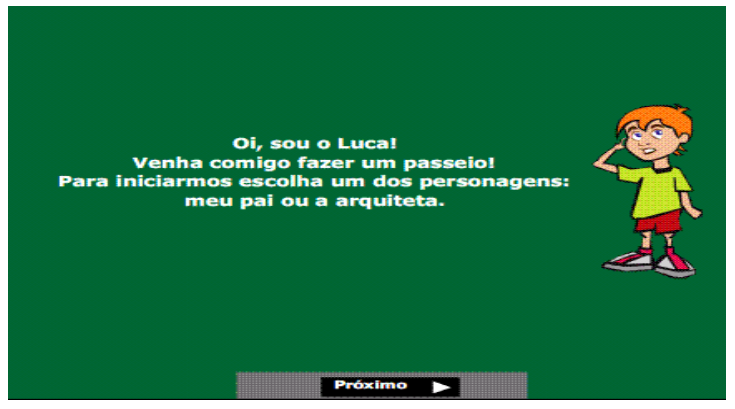

Figura 1- Apresentação de Luca

Alguns conceitos prévios são necessários para o aluno, tais como: operações com frações, operação com números decimais e conversão de unidades de medidas, conteúdos estes que foram trabalhados nas séries anteriores.

A tela seguinte, conforme figura 2, possui duas opções de entrada, e fica a critério do usuário escolher em qual desses contextos irá desenvolver as demais atividades. Se clicar sobre a arquiteta, irá desenvolver a atividade relacionada com plantas de casas; e se clicar sobre o pai de Luca, segue a atividade de mapas. 


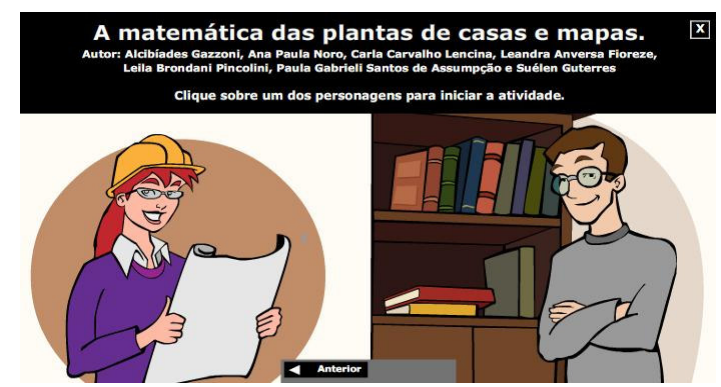

Figura 2 - Arquiteta e pai de Luca

Supondo que o usuário clicou sobre o pai de Luca, irá iniciar a atividade referente ao mapa de uma cidade onde Luca e seu pai estavam a passeio pela praça desta cidade. Tudo transcorre quando em um certo momento Luca observa um mapa exposto na praça e decide ir até ele para ver do que tratava, conforme a figura 3.

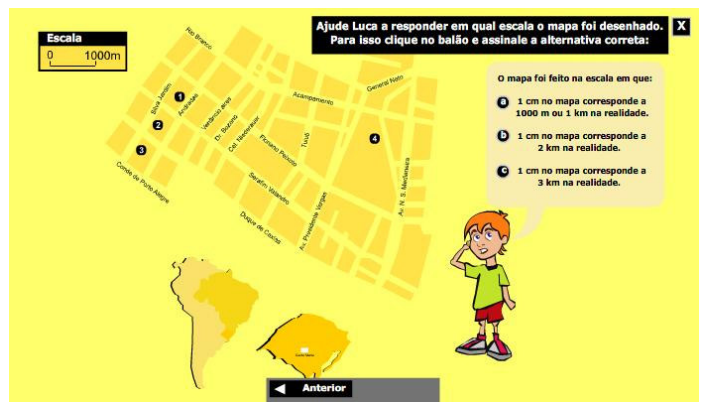

Figura 3 - Praça da cidade

Observando o mapa percebem que é o da cidade onde eles moram e a partir disto Luca faz algumas perguntas a seu pai. Através das respostas dadas pelo seu pai, Luca tem uma noção do conceito de escalas e mostra - se então a primeira atividade onde o aluno deve identificar a escala em que o mapa foi desenhado.

A seguir, para responder com melhor compreensão as demais perguntas propostas por Luca, seu pai o leva até a biblioteca que fica do outro lado da praça. Nesse ambiente, Luca e seu pai observam alguns mapas expostos na parede, conforme a figura 4.

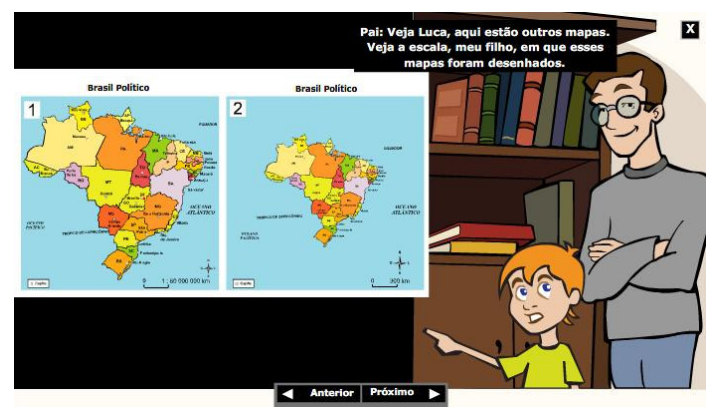

Figura 4 - Mapas 
Dentre as atividades propostas, uma delas é identificar em qual escala os mapas foram desenhados, para isso o usuário deverá clicar sobre um dos mapas destacados, preencher o espaço em branco e confirmar a resposta clicando no botão "ok ". Ainda observando os mapas na biblioteca, o aluno será instigado a descobrir a escala em que um mapa foi desenhado, conhecendo a distância entre duas cidades (figura 5).

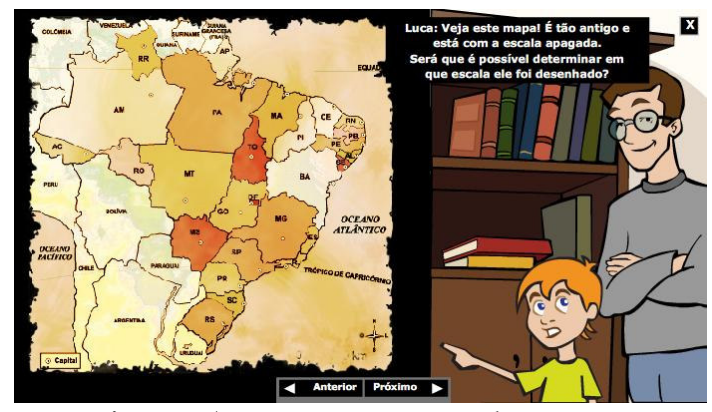

Figura 5 - Mapa sem escala

Outra atividade deste objeto é responder qual o par de cidades que, na realidade, está mais próximo, conforme a figura 6, e para isso o usuário deverá medir a distância com a régua, que faz parte deste objeto, relacionar com a escala do mapa e clicar em uma das alternativas dadas.

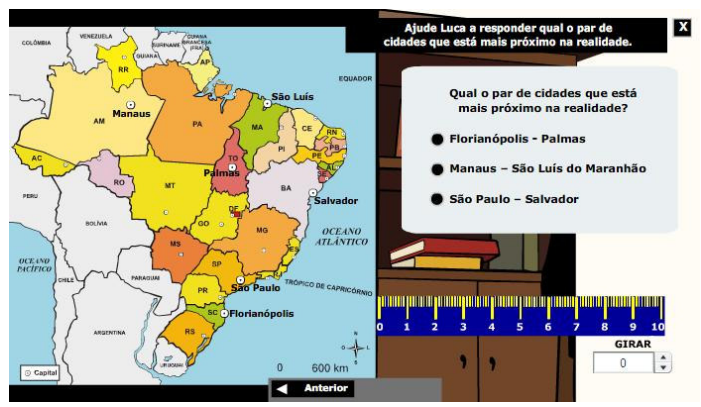

Figura 6 - Distância entre as cidades

Porém, se o usuário escolher fazer o passeio com a arquiteta no início da atividade, então segue a estória relacionada a plantas de casas. Na primeira tela, aparece o personagem conversando com a arquiteta que fez o desenho da planta da casa que seus pais estão construindo, veja a figura 7 .

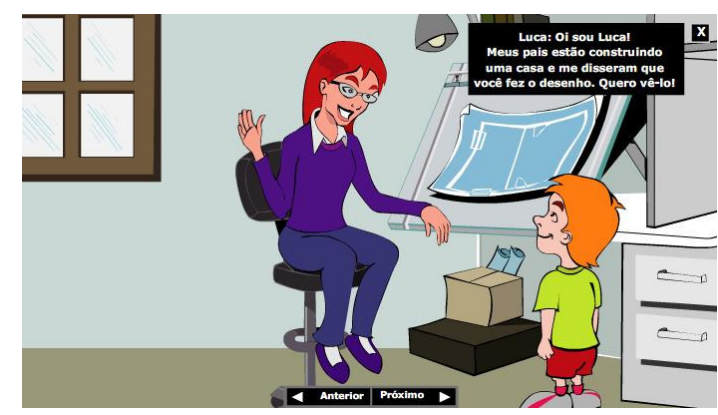

Figura 7 - Arquiteta e Luca

Uma atividade proposta nessa seção consiste em medir as dimensões da planta, conforme figura 8 , e dar suas dimensões reais. Para isso o usuário utiliza a régua para 
fazer medições e determiná-las na realidade, utilizando a escala em que a planta foi desenhada, preenchendo os espaços em branco com a resposta e confirmando no botão ok.

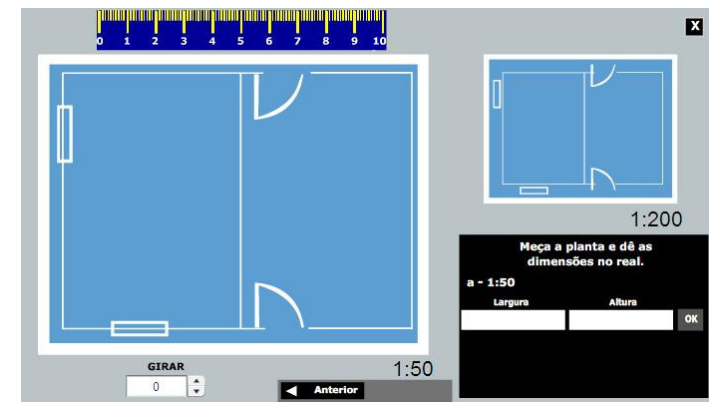

Figura 8 - Planta da casa

Visando contribuir com a aprendizagem do conteúdo do Objeto de Aprendizagem A matemática das plantas de casas e mapas, procurou-se oportunizar situações interativas. O termo interação (Tajra, 2002) é composto de um prefixo derivado do latim (inter) e um núcleo, também derivado do latim (actiõ - ação) que possui os respectivos significados: inter - entre, no meio de; ação: atuação, ato, feito, obra. Ambientes interativos e os computadores apresentam um papel fundamental ao propiciar o uso de ferramentas que apóiam e possibilitam a comunicação e a interação entre os sujeitos. É através das interações que os sujeitos desencadeiam trocas, estratégias de construção/autoria, compartilhamento de idéias, possibilitando gerar novas interações.

\section{Considerações Finais}

Com o objeto Matemática nas Plantas de Casas e Mapas, são oportunizadas ao aluno situações que permitem mobilizar os campos algébrico, geométrico e aritmético necessários para a aprendizagem de escalas e proporcionalidade. Isto é feito na comparação entre medidas obtidas em diferentes escalas; na comparação entre elementos de uma seqüência de medidas para determinar a razão de proporcionalidade entre elas; na ampliação ou na redução de figuras geométricas a fim de acomodá-las em um espaço pré-determinado.

Por meio de atividades digitais, é possível proporcionar situações interativas, utilizando-se também de animações e simulações que permitirão ao aluno a visualização de diferentes possibilidades, fornecendo feedback imediato.

Esta experiência na elaboração desse objeto de aprendizagem e de outro premiado no concurso RIVED/2006 (Proporcionalidade e Semelhança, disponível no site do RIVED), propiciou experiência ao grupo de professores e alunos na construção de outros objetos.

Outro objeto de aprendizagem está em fase de finalização, que é o de Seqüências Numéricas no Ensino Fundamental. Abordando novos temas e contribuindo para a construção de recursos tecnológicos digitais e sua inserção nas escolas, busca-se contribuir para a qualificação do processo ensino-aprendizagem de Matemática e também para a apropriação da construção e utilização destes recursos pelo futuro professor de matemática. 


\section{Referências Bibliográficas}

BALACHEFF, N., KAPUT, J. Computer-Based Environments in Mathematics, pp. 469-501. En International Handbook of Mathematical Education, Bishop, A. Et al (eds), Kluwer Academic Publishers, 1996.

BASSO, M. Espaços de aprendizagem em rede: novas orientações na formação de professores de matemática. Porto Alegre: Universidade Federal do Rio Grande do Sul, 2003, 412f. Tese (Doutorado em Informática na Educação) - PGIE, UFRGS, Porto Alegre, 2003.

CABRAL, T. C. P. Ensino e aprendizagem de matemática na engenharia e o uso de tecnologia. In: RENOTE Revista Novas Tecnologias na Educação, v. 3, n. 2, Novembro, 2005. Disponível em:

http://www.cinted.ufrgs.br/renote/nov2005/artigosrenote/a34 engenharia.pdf. Acesso em 29 out. 2007

FAGUNDES, L, ; SATO L. S.; MAÇADA, D. L. Aprendizes do futuro: as inovações começaram. Brasília: MEC, 1999. Coleção Informática para a Mudança em Educação/Mec/Seed/Proinfo.

REDE INTERATIVA VIRTUAL DE EDUCAÇÃO. Secretaria de Educação à Distância. Brasília, Ministério da Educação, 2007. Disponível em:

$<$ http://rived.proinfo.mec.gov.br>. Acesso em: 12 mar. 2007.

TAJRA, Snmya Feitosa. Comunidades Virtuais: Um fenômeno na Sociedade do conhecimento. SP: Érica, 2002.

TINOCO, L. Razões e Proporções. Rio de Janeiro: UFRJ, 1996.

VERGNAUD, Gerard. Algunas ideas fundamentales de Piaget em torno de la didactica. In: Perspectivas: revista trimestral de educación comparada - Caderno: Piaget e lá educación. Paris: UNESCO, Oficina Internacional de Educación, vol. XXVI, n. 1, p. 195-207, março, 1996.

WILLEY, D. Connecting learning objects to instructional design theory: A definition, a metaphor, and a taxonomy. 2000. Disponível em: <http://www.reusability.org/read/chapters/wiley.doc. Acesso em: 29 mar. 2008. 